\title{
Analysis and modeling of highway truck traffic volume variations during severe winter weather conditions in Canada
}

\author{
Hyuk-Jae Roh $^{1} \cdot$ Satish Sharma ${ }^{2} \cdot$ Prasanta K. Sahu $^{3} \cdot$ Sandeep Datla $^{4}$
}

Received: 27 February 2015/Revised: 25 June 2015/Accepted: 1 July 2015/Published online: 24 July 2015

(C) The Author(s) 2015. This article is published with open access at Springerlink.com

\begin{abstract}
This paper investigates the impact of cold and snow on daily and hourly truck traffic volume on a primary highway in Alberta, Canada. This research is based on a detailed case study of 5 years of weigh-in-motion data recorded continuously at Leduc site on Highway 2A. Influence of the winter conditions on truck type distribution is examined by classifying trucks into single-unit trucks, single-trailer, and multi-trailer units. It is evident from the study that proportion of the three truck classes in the total truck traffic remained essentially stable over the study period (2005-2009). Dummy-variable regression models are used to relate daily and hourly truck traffic volume with snowfall and categorized cold as independent variables. The statistical significance of all the independent variables used in the model is established by conducting tests such as $R^{2}, F$ test, incremental $F$ test, and $t$ test. The study results suggested that the truck volume is not significantly affected by the normal snowfall or the typical cold temperatures, i.e., average daily snowfall about less than $15 \mathrm{~cm}$ or
\end{abstract}

Hyuk-Jae Roh

hyukjae.roh@gmail.com

Satish Sharma

satish.sharma@uregina.ca

Prasanta K. Sahu

prasantsahu222@gmail.com

Sandeep Datla

sandeepdatla@gmail.com

1 City of Regina, Regina, SK, Canada

2 Faculty of Engineering and Applied Science, University of Regina, Regina, SK, Canada

3 Department of Civil Engineering, Birla Institute of Technology Pilani, Pilani 333031, Rajasthan, India

4 City of Edmonton, Edmonton, AB, Canada temperatures higher than $-25{ }^{\circ} \mathrm{C}$ are not likely to affect the truck traffic patterns. It is believed that the findings of this study can benefit highway agencies in developing programs and policies for efficient monitoring of truck traffic throughout the year and snow removal during the winter season in Canada.

Keywords Truck traffic - Snowfall - Cold temperature · Weather $\cdot$ Alberta $\cdot$ Canada

\section{Introduction}

Traffic volume varies over time and locations on all roadways. Even if traffic streams are investigated for the same time and location, the variations in traffic volume could differ substantially when each vehicle class traveling in the traffic stream is analyzed separately. Severe winter weather conditions in Canada and northern regions of the USA are another factor for traffic stream variations [1,2]. Datla and Sharma [1] studied the impact of winter weather conditions (cold temperatures and snowfall) on highway traffic volume. Their study concluded that winter weather causes significant variations in traffic volume, and the magnitude of variation depends on the time of day, day of the week, location, highway type, and severity of the weather. However, their study and other similar studies published in the literature are limited to total traffic only. Studies on truck traffic variations during severe winter conditions are next to non-existent, whereas research on truck traffic could be very useful for transportation analyses for such purposes as developing programs and policies for efficient winter road maintenance programs, structural and geometric design of pavement, highway life cycle analysis, project prioritization, etc. 
The main purpose of this study is (1) to investigate the influence of the winter conditions (snow, temperature) on different types of trucks and (2) to analyze the impact of winter weather conditions on daily and hourly truck volume. Two types of temporal variations of truck type distributions are investigated: (1) month-to-month variations and (2) season-to-season variations in which the months of November to March representing severe snowfall and cold conditions are grouped into winter months and the remaining months are grouped into non-winter months. Combined Chi squared $\left(\chi^{2}\right)$ and Binomial tests of statistical significance are conducted to investigate the variations for the three truck classes during winter weather conditions. Dummy-variable regression models are developed to define quantitatively the variations in daily and hourly truck volumes under different weather conditions. The study uses weigh-in-motion (WIM) data collected from Leduc site located on a provincial highway: highway $2 \mathrm{~A}$ in Alberta, Canada. The modeling work for the present research is carried out using CARPACKAGE, available in the statistical software R [3]; RDCT [4].

\section{Relevant past studies}

A majority of studies in literature reported quantitative association of total traffic volume with weather conditions i.e., magnitude of reduction in total traffic volume due to different weather conditions. Datla and Sharma [1] studied the impact of cold and snow on daily and hourly traffic volume for provincial highways in Alberta, Canada. Maze et al. [5] studied the weather effect on traffic demand, traffic flow relationships, and traffic safety for Inter-state Highway 35 in northern rural Iowa. They reported a strong correlation between the percentage reduction in traffic volume with wind speed and visibility during snowy days. Keay and Simmonds [6] reported the association of rainfall and other weather variables with traffic volume on urban arterials in Melbourne, Australia. Knapp and Smithson [2] analyzed the average traffic reductions on inter-state highways in Iowa State during winter storms. For Lothian region, Scotland, Hassan and Barker [7] studied the association of traffic with meteorological parameters such as minimum and maximum temperatures, snow and rain fall, snow on ground, and sunshine hours. Changnon [8] studied the impact of variations in summer precipitation patterns on travel patterns in Chicago. Hanbali and Kuemmel [9] studied the average traffic volume reductions due to snow storms on rural highways in the United States. Several other studies have also reported variations in traffic volume levels and changes in traffic patterns during adverse weather conditions. However, none of the past studies presented the impact of weather conditions on truck traffic with consideration of highway type.
Described in this paper is an investigation of the impact of cold and snow on trucks in the traffic stream.

\section{Study data}

The provincial highway agency in Alberta, Canada, collects vehicle-by-vehicle WIM data at six highway sites on its network. As shown in Fig. 1, the WIM station selected for this research is located south of Leduc (near the City of Edmonton) on control Sect. 26 of Highway 2A (2 lanes) and is referred to as LEDUC site in this paper. The two main reasons for selecting this site for the study are as follows: (1) the site is located close to southern boundary of City of Edmonton, which is the 5th largest City in Canada, (2) there are no missing hourly traffic records at this site over the study period (2005-2009), and (3) there are several potential weather stations in proximity that could be used to extract snowfall and temperature data. The LEDUC site serves both local and regional truck traffic with an AADT of over 6,000 vehicles per day. The truck traffic at this site is about $8 \%$ of the total traffic.

Weather data were collected from Environment Canada weather information archives [10]. There are 598 weather stations operated by Environment Canada in the province of Alberta. The weather stations provide detailed weather parameters such as maximum, minimum, and mean temperature (measured in ${ }^{\circ} \mathrm{C}$ ), total rain (millimeters), total snowfall (centimeters), total precipitation (millimeters), and snow on ground (centimeters) on daily basis. Details of raw data format and measuring methods for each of these weather parameters are available from the Environment Canada website [10]. Based on the research done by Andrey and Olley [11] and Datla and Sharma [1] and using proximity analysis module in ArcGIS 10 [12], the weather station labeled 3012205 is chosen for our analysis. This is the closest $(13 \mathrm{~km})$ weather station to LEDUC without any missing data.

\section{Methodology}

The methodology for this study includes two steps: (1) truck type classification and analysis of winter impact on truck type distribution and (2) developing winter weather truck traffic models. Based on desk research on different vehicle classification methods, Federal Highway Administration (FHWA) 13-category classification scheme is selected to classify the vehicles from WIM data [13]. This scheme was developed in 1985 by Maine Department of Transportation (Maine DOT) and is called "scheme F." This classification scheme is a standard scheme adopted by several highway agencies in North America. We used this FHWA scheme for 


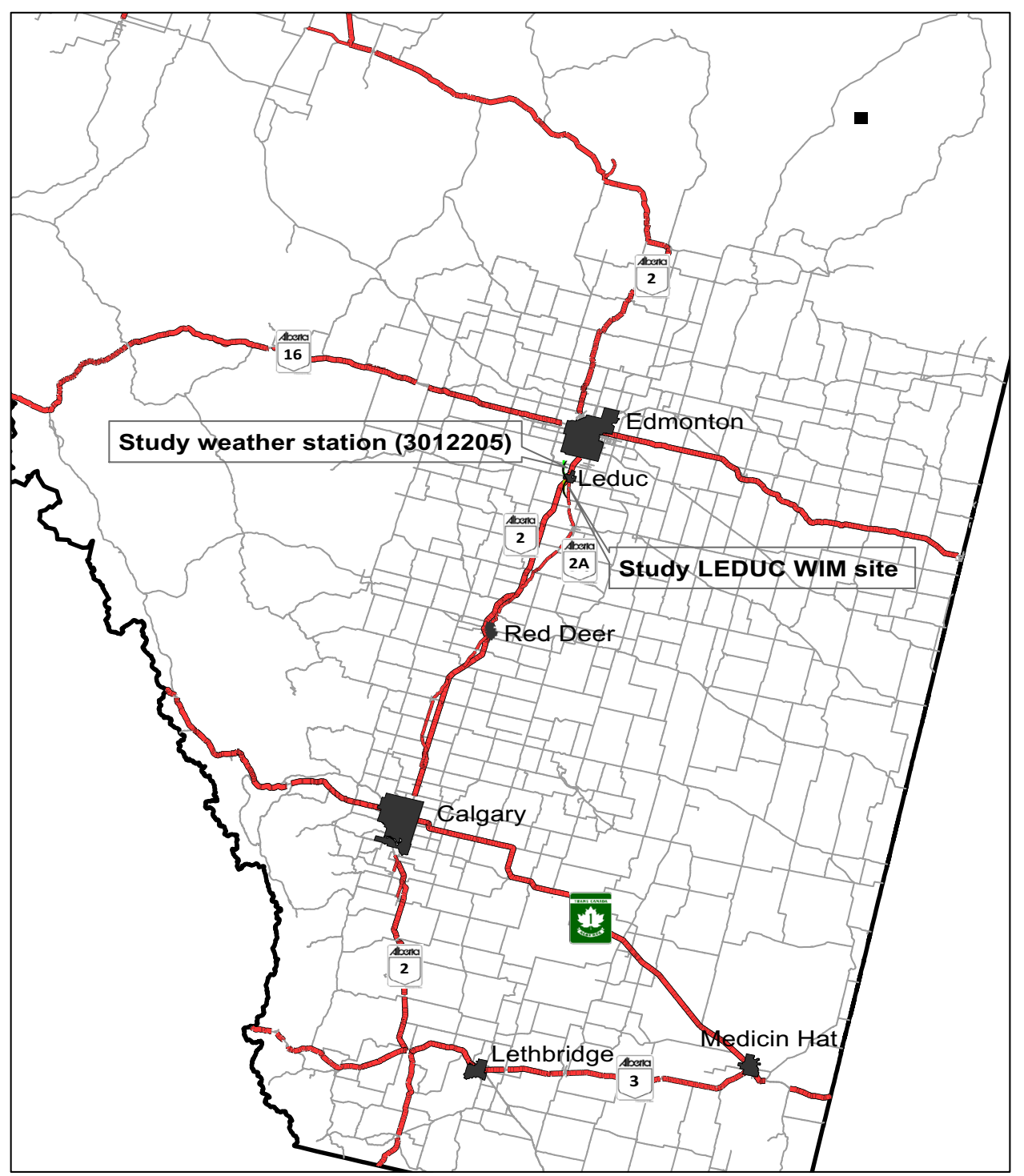

Fig. 1 Thematic map showing cities in Alberta, study WIM site, weather station, and highway network

our study, and the classification process is resulted in 28 vehicle classes. However, we could not generate sufficient samples to carry out detailed statistical analysis by each vehicle class because of lower number of total trucks in general and too many truck classes. Therefore, the 28 vehicle classes are aggregated into three major categories: singleunit trucks, single-trailer, and multi-trailer units. We carried out two statistical tests: $\chi^{2}$ test and Binomial probability (BP) test to understand the association of winter weather with these three truck classes. As already indicated in the previous section that truck traffic share is only about $8 \%$ of total traffic for this study site, we used the total truck for the purpose of mathematical modeling.

Historical weather records from the Environment Canada [10] climate database indicated that the province of Alberta experiences severe snowfall and cold conditions from November to March. Based on this observation, this research is limited to only the months of 'November-March' during the study years. Since traffic patterns during long weekend statutory holidays in Alberta are very unique, special attention is needed to conduct research using data from holidays and their neighboring days [14]. For this reason, three holidays included in the study period (New Year's Day, Alberta Family Day (3rd Monday of February), and Christmas day) are excluded from the study.

\subsection{Analysis of truck type distribution during winter months}

We examined the association of truck type distribution with the winter months using combined $\chi^{2}$ and BP 
distribution tests. The $\chi^{2}$ test checks the goodness of fit of a data set by comparing the expected and observed patterns of the data [15]. In this study, the average monthly truck type distribution patterns during the analysis period is considered as one empirical frequency distribution. The other empirical frequency distribution, i.e., the expected truck type distribution, patterns are calculated based on the null hypothesis, i.e., "truck type distribution is not associated with the month." If the two truck type distribution patterns are similar to each other, a close agreement is expected between the observed and expected frequencies with the estimated $\chi^{2}$ values smaller than critical value. The $\chi^{2}$ test results are presented in Table 1 . The $\chi^{2}$ test procedure is described in detail in Roh et al. [16].

The $\chi^{2}$ test results reveal only whether or not truck types are associated with the months of a given year, so the results may not be conclusive. The BP test is used to develop adequate confidence on repeatability of yearly $\chi^{2}$ test results. It is expected that $\chi^{2}$ test result follows BP distribution with the probability value of a success of 0.5 on each year, where the sample size equals the number of study years. The critical value of number of significant years is found to be 4 with a sample size of 5 at $95 \%$ confidence level from the BP distribution table. Based on the combined $\chi^{2}$ and BP test results, it can be concluded that the truck type distribution is not associated with the winter months for the LEDUC site. Because of data limitations (both temporal: number of years, and spatial: number of WIM sites), more in-depth seasonal variations in truck traffic could not be established with a high confidence level. Moreover, the impact of severe weather on truck traffic may be very high during the storm periods and truck traffic resumes to normal conditions when the weather conditions become normal. Such changes in truck traffic patterns may normalize when the monthly variations are observed. Next section investigates the impact of weather on truck traffic at daily level and hourly level. Nevertheless, the above findings would be useful for truck traffic monitoring programs.

Table 1 Summary of Chi squared $\left(\chi^{2}\right)$ test results

\begin{tabular}{lrl}
\hline Year & $\chi^{2}$ leduc & Significance** \\
\hline 2005 & 241.235 & $\mathrm{Y}$ \\
2006 & 21.023 & $\mathrm{~N}$ \\
2007 & 62.156 & $\mathrm{Y}$ \\
2008 & 67.809 & $\mathrm{Y}$ \\
2009 & 17.363 & $\mathrm{~N}$ \\
Total significant years & & 3
\end{tabular}

** $Y$ dependent on month, $N$ independent on month

\section{Winter weather truck traffic model}

In this study, we used standard additive regression approach to relate truck traffic variation with winter weather conditions. The winter conditions are described by snowfall and daily average temperature; these two variables are used as explanatory variables in the model formulation. The other independent variable included in the model is the expected daily volume for trucks. Normalized daily truck volumes (truck volume-to-truck AADT ratio) are used instead of actual volumes to consider the annual variations in truck volume. The expected daily volume factor (EDVF), which is used as one of the independent variables, is calculated using the historical data for each day of a given week of a specific month.

The appropriateness of these independent variables is examined through scatter plot matrix and correlation coefficient. The scatter plot diagnostic suggested linear association between the daily truck volume with the EDVF, snowfall, and temperature. Histograms (with the estimated probability density function) of temperature for the days with snow and without snow were constructed. The results indicated that average temperature was colder during the days with snowfall $\left(-10.94{ }^{\circ} \mathrm{C}, 160\right.$ days $)$ than the nosnowfall days $\left(-8.08{ }^{\circ} \mathrm{C}, 350\right.$ days). A correlation analysis was also conducted between snowfall and temperature. The correlation coefficients ranged from 0.03 to -0.18 , which means that little to no correlation exists between snowfall and temperature. This observation justified the inclusion of both snow and cold as independent variables in the model. Although other weather factors (wind, pavement conditions, etc.) also cause variations in daily traffic volumes, this research is limited to snow and temperature.

\subsection{The daily model}

We used dummy-variable regression model structure for analyzing the winter weather impact on truck traffic. For the purpose of mapping the relationships between daily traffic volume and weather factors, a dummy-variable regression model is proposed with two quantitative variables, i.e., EDVF and snow, and one categorical variable, i.e., temperature, which is categorized into seven categories at $5{ }^{\circ} \mathrm{C}$ intervals: $\mathrm{CC}_{1}\left(-5 \sim 0{ }^{\circ} \mathrm{C}\right), \mathrm{CC}_{2}\left(-10 \sim-5{ }^{\circ} \mathrm{C}\right), \mathrm{CC}_{3}$ $\left(-15 \sim-10^{\circ} \mathrm{C}\right), \quad \mathrm{CC}_{4} \quad\left(-20 \sim-15{ }^{\circ} \mathrm{C}\right), \quad \mathrm{CC}_{5}$ $\left(-25 \sim-20^{\circ} \mathrm{C}\right.$ ), and $\mathrm{CC}_{6}$ (below $-25^{\circ} \mathrm{C}$ ). The baseline category (the days having over $0{ }^{\circ} \mathrm{C}$ ) is omitted in the model specifications because it is the reference category to which the other categories are compared. The additive dummyregression daily model structure is given in Eq. 1: 
$y_{i}=f($ expected daily volume factor, snowfall, temperature $)$

$$
=\beta_{1} E D V F_{i}+\beta_{2} S N O W_{i}+\sum_{j=1}^{6} \gamma_{j} C C_{i j}+\xi_{i}
$$

where $i$ refers to the ith observation, $\beta_{1}, \beta_{2}$, and $\gamma_{1 \sim 6}$ are the regression coefficients estimated for the independent variables, $y_{i}$ is the estimated value of daily truck traffic volume factor, $E D V F$ is the expected daily volume factor calculated from the historically observed data, $S N O W$ is the amount of snowfall per day $(\mathrm{cm}), C C_{i 1 \sim 6}: C C_{i j}=1$ if observation $i$ falls in category $j$, otherwise 0 , and $\xi_{i}$ is the stochastic error term.

The preliminary analysis of the study data suggested different truck traffic patterns for weekdays and weekends. Therefore, 2 separate models are calibrated for weekdays and weekends using ordinary least-square regression method. The calibration results are discussed in the following section.

\section{Results and discussion}

The calibrated models are presented in Tables 2 and 3. Table 2 presents the truck traffic weekday model and weekend truck model is presented in Table 3 along with the statistical test results. The overall goodness of fit of model is evaluated by the regression coefficient $\left(R^{2}\right)$ value. The $R^{2}$ values for all models are greater than 0.98 , which indicated that the models fit well to the sample data. The $F$ statistic value is used to assess the overall adequacy of the model and found to be statistically significant at 0.001 level. The incremental $F$ statistic values are used to test the null hypothesis of "no partial effect of cold categories $\left(H_{0}: \gamma_{1}=\gamma_{2}=\cdots \gamma_{6}=0\right)$. By comparing the categorical regression model's $R^{2}$ value and $R^{2}$ of naive model, i.e., $y_{i}=\beta_{1} E D V F_{i}+\beta_{2} S N O W_{i}+\xi_{i}$ it is possible to confirm whether or not the inclusion of dummy variables is statistically significant. Below is an example for weekday truck traffic model:

$F=\frac{\left(R_{\text {dummy }}^{2}-R_{\text {Naive }}^{2}\right) /\left(K_{\text {dummy }}-K_{\text {Naive }}\right)}{\left(1-R_{\text {dummy }}^{2}\right) /\left(N-K_{\text {dummy }}\right)}$

$F=\frac{(0.9925-0.9923) /(9-2)}{(1-0.9925) /(355-9)}=1.318$

where $R_{\text {dummy }}^{2}$ is the value of $R^{2}$ including dummy variables for weekday truck traffic model, $R_{\text {Naive }}^{2}$ is the comparable measure for the naive model without dummy variables, $N$. the number of observations (days), $k_{\text {dummy }}$ is the total number of independent variables including dummy variables (equal to 9), and $k_{\text {naive }}$ is the total number of independent variables without including dummy variables (equal to 2). The increment in $F$ statistics value is marginal (1.381). The statistical significance for individual coefficients is evaluated by the $t$ statistic, and the significance level is indicated using a symbol $(*)$ in Tables 2 and 3 . Based on the results of the $t$ tests, it is found that the incremental $F$ statistics value is not significant. In other words, the truck volume is not significantly affected by the

Table 2 Results of daily factor model by vehicle classes using dummy-variable regression for weekday

\begin{tabular}{lll}
\hline Variables & Truck traffics & Seven fitted regression equations for each cold category for trucks \\
\hline EDVF & $1.007501(0.057602)^{* * *}$ & $\hat{Y}_{\text {baseline }}=1.007501 \times E D V F-0.006312 \times S N O W-0.027909$ \\
SNOW & $-0.006312(0.003332)$ & $\hat{Y}_{\mathrm{cc} 1}=1.007501 \times E D V F-0.006312 \times S N O W-0.008577$ \\
Baseline & $-0.027909(0.069444)$ & $\hat{Y}_{\mathrm{cc} 2}=1.007501 \times E D V F-0.006312 \times S N O W+0.003400$ \\
$\mathrm{CC}_{1}$ & $-0.008577(0.066942)$ & $\hat{Y}_{\mathrm{cc} 3}=1.007501 \times E D V F-0.006312 \times S N O W+0.002056$ \\
$\mathrm{CC}_{2}$ & $0.003400(0.065081)$ & $\hat{Y}_{\mathrm{cc} 4}=1.007501 \times E D V F-0.006312 \times S N O W+0.015670$ \\
$\mathrm{CC}_{3}$ & $0.002056(0.065545)$ & $\hat{Y}_{\mathrm{cc} 5}=1.007501 \times E D V F-0.006312 \times S N O W+0.018095$ \\
$\mathrm{CC}_{4}$ & $0.015670(0.067165)$ & \\
$\mathrm{CC}_{5}$ & $0.018095(0.068178)$ & \\
$\mathrm{CC}_{6}$ & $-0.070536(0.067484)$ & \\
$R^{2}$ & 0.9925 & \\
$F$ & $5,113^{* * *}$ & \\
Change from $R_{\text {Naive }}^{2}$ & 0.0002 & \\
Incremental $F$ statistic & 1.318 & \\
Number of days & 355 &
\end{tabular}

Regression coefficients with standard errors (in parentheses)

*** Coefficient is statistically significant at the 0.001 level, ** 0.01 level, * 0.05 level 
Table 3 Results of daily factor model by vehicle classes using dummy-variable regression for weekend

\begin{tabular}{|c|c|c|}
\hline Variables & Truck traffics & Seven fitted regression equations for each cold category for trucks \\
\hline EDVF & $1.029443(0.066545)^{* * *}$ & \multirow{13}{*}{$\begin{array}{l}\hat{Y}_{\text {baseline }}=1.029443 \times E D V F+0.002297 \times S N O W-0.031033 \\
\hat{Y}_{\mathrm{cc} 1}=1.029443 \times E D V F+0.002297 \times S N O W-0.024497 \\
\hat{Y}_{\mathrm{cc} 2}=1.029443 \times E D V F+0.002297 \times S N O W-0.027667 \\
\hat{Y}_{\mathrm{cc} 3}=1.029443 \times E D V F+0.002297 \times S N O W+0.002300 \\
\hat{Y}_{\mathrm{cc} 4}=1.029443 \times E D V F+0.002297 \times S N O W+0.030674 \\
\hat{Y}_{\mathrm{cc} 5}=1.029443 \times E D V F+0.002297 \times S N O W+0.007679 \\
\hat{Y}_{\mathrm{cc} 6}=1.029443 \times E D V F+0.002297 \times S N O W-0.031499\end{array}$} \\
\hline SNOW & $0.002297(0.003221)$ & \\
\hline Baseline & $-0.031033(0.037673)$ & \\
\hline $\mathrm{CC}_{1}$ & $-0.024497(0.033887)$ & \\
\hline $\mathrm{CC}_{2}$ & $-0.027667(0.032101)$ & \\
\hline $\mathrm{CC}_{3}$ & $0.002300(0.034327)$ & \\
\hline $\begin{array}{l}\mathrm{CC}_{4} \\
\mathrm{CC}_{5}\end{array}$ & $\begin{array}{l}0.0306 / 4(0.035667) \\
0.007679(0.034058)\end{array}$ & \\
\hline $\mathrm{CC}_{6}$ & $-0.031499(0.039203)$ & \\
\hline$R^{2}$ & 0.9819 & \\
\hline$F$ & $759.3 * * *$ & \\
\hline Change from $R_{\text {Naive }}^{2}$ & 0.0016 & \\
\hline Incremental $F$ statistic & 1.59 & \\
\hline Number of days & 135 & \\
\hline
\end{tabular}

Regression coefficients with standard errors (in parentheses)

*** Coefficient is statistically significant at the 0.001 level, ** 0.01 level, * 0.05 level

(c) Trucks

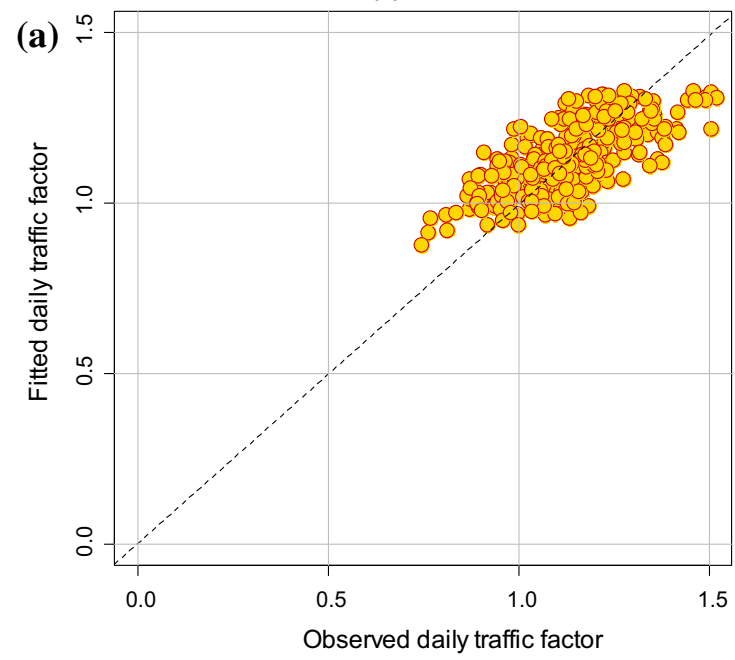

Trucks

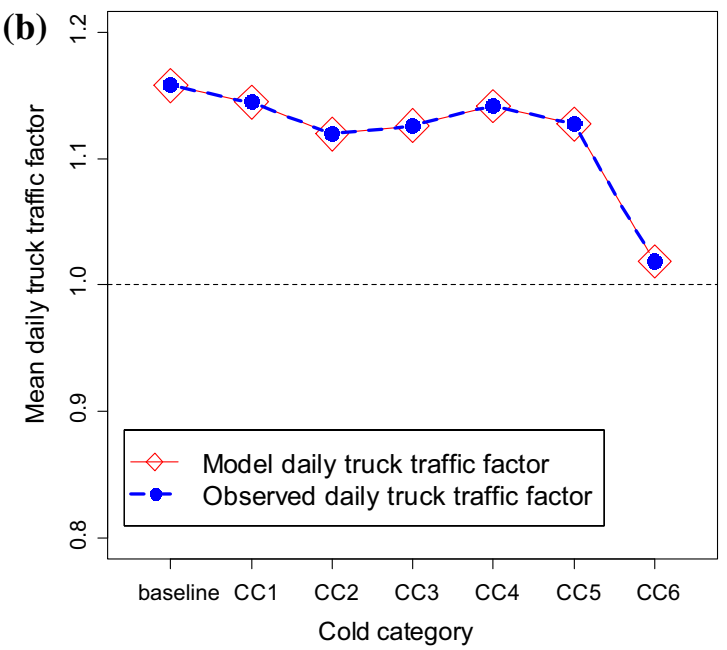

Fig. 2 Results of dummy-variable regression models of weekdays for trucks. a Scatter plot for fitted and observed factors and $\mathbf{b}$ line plot for modeled and observed factors for cold category

snowfall or the cold categories for both weekday and weekend truck traffic models as presented in Tables 2 and 3 , respectively.

The variations of estimated and observed truck traffic factors are presented in Figs. 2 and 3. A regression line is fitted in the same plot to show the level of closeness between the two values. It is worth noting that the weekday truck traffic factors are generally clustered between the values of 0.90 and 1.30 (see Fig. 2a). However, the weekend daily truck factors are between 0.30 and 0.70 (see Fig. 3a). This means that the LEDUC site carries much lower average daily truck traffic volume over the weekend as compared to weekday truck traffic volume. The accuracy of the calibrated models in terms of estimating the mean daily traffic factor for the seven temperature categories is shown with the help of line graphs in Figs. $2 \mathrm{~b}$ and $3 \mathrm{~b}$. The dotted line with solid circles shows the mean values of observed daily traffic factors in each of the seven cold categories, and the solid line with diamonds shows the mean values of daily traffic factors estimated using the proposed model. It should be noted that the observed and the estimated mean values of the daily truck volume factors for all cold categories are so close that the two lines overlap each other in the plots.

The partial effect of snow and cold on truck volume is presented graphically in Figs. 4 and 5. The solid line shows 
(c) Trucks

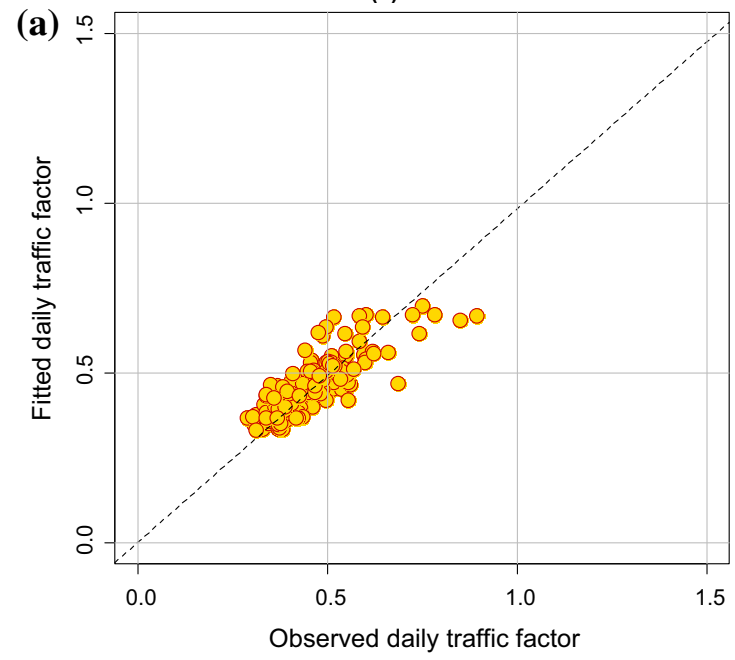

Trucks

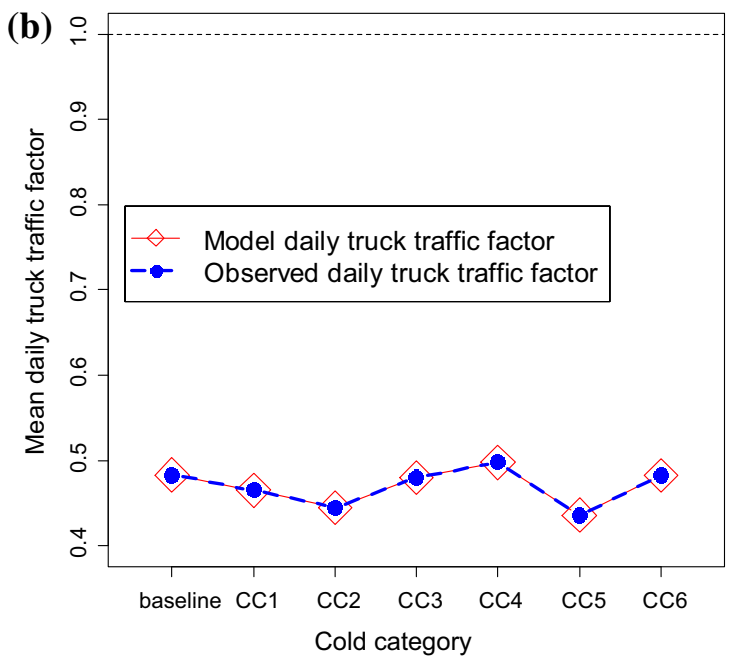

Fig. 3 Results of dummy-variable regression models of weekends for trucks. a Scatter plot for fitted and observed factors and $\mathbf{b}$ line plot for modeled and observed factors for cold category

(a)

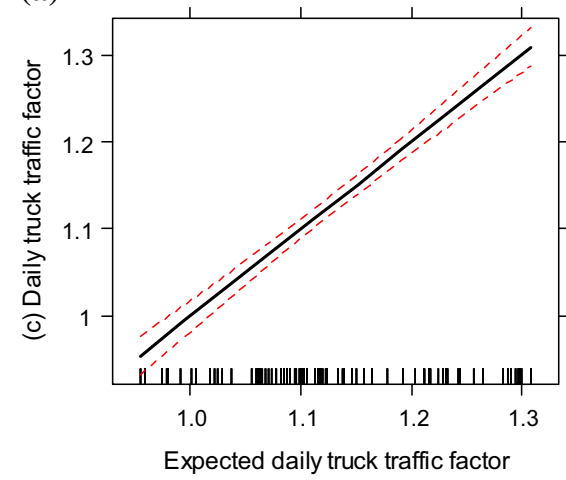

(b)

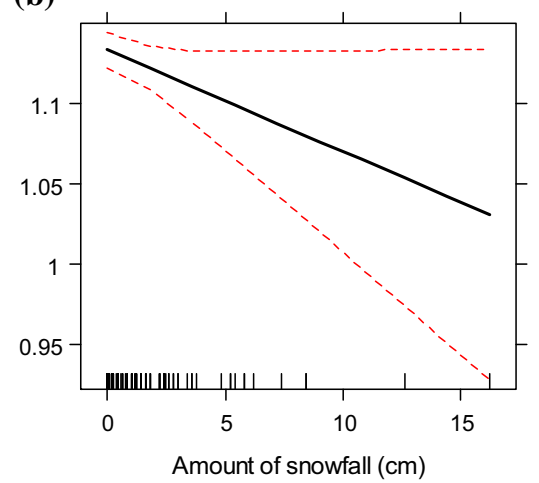

(c)

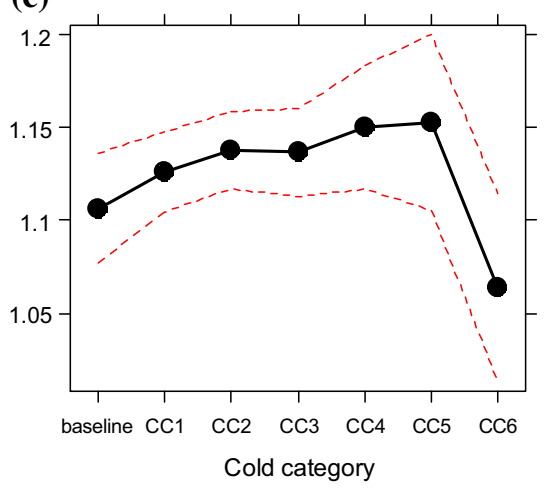

Fig. 4 Partial effect of snow and cold on daily weekday truck volume. a Effect of EDVF on daily volume, b effect of SNOW on daily volume, and $\mathbf{c}$ effect of COLD on daily volume

the estimated values from the calibrated model, while the dotted lines give $95 \%$ confidence intervals around the model estimates. The models shown in Tables 2 and 3 are used to develop plots of the partial effect of EDVF on daily volume factor, and they are generated by fixing $S N O W$ to its average value in the sample data and keeping the temperature at a weighted mean value for the seven cold categories. These plots are shown Figs. $4 \mathrm{a}$ and $5 \mathrm{a}$ for weekdays and weekends, respectively. The distribution of EDVF values is shown on the $x$ axis of the graph with a one-dimensional scatter bar. A similar procedure is followed to develop plots for the partial effect of SNOW (see Figs. $4 \mathrm{~b}$ and $5 \mathrm{~b}$ ). In this case, EDVF is fixed at its average and the temperature is kept at its weighted mean value. The partial effect of cold is plotted in Figs. $4 c$ and $5 c$. In this case, both EDVF and SNOW are fixed at their average values to compute the estimated value of daily traffic volume factor for each cold category.

Figures $4 \mathrm{a}$ for weekday and 5a for weekend clearly show a close and positive relation between EDVF and the daily traffic volumes. Also, these two plots show a similar trend. The partial effect of SNOW on daily truck traffic volumes for weekday is exhibited in Fig. $4 \mathrm{~b}$ and for weekend in Fig. 5b. There is a very gentle and insignificant decrease in the daily truck traffic with an increase in snowfall for weekday truck traffic. In the case of weekend, the plots for snow indicate an upward trend which is not statistically significant. Overall, the partial effects of snowfall on daily truck traffic factors are insignificant.

The partial effect of cold categories on weekday truck traffic is presented in Fig. $4 \mathrm{c}$, and the mean daily traffic factor does not appear to change considerably for 

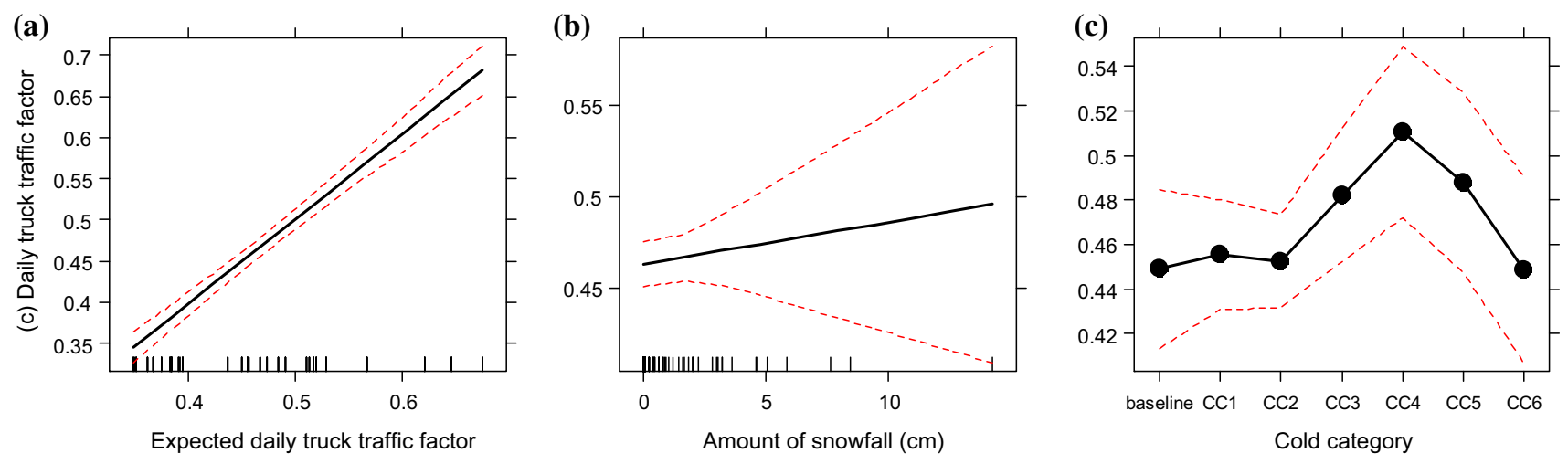

Fig. 5 Partial effect of snow and cold on daily weekend truck volume. a Effect of EDVF on daily volume, b effect of SNOW on daily volume, and $\mathbf{c}$ effect of COLD on daily volume

categories up to CC5. There is a little drop (1.15-1.07) in the mean factor for CC6. However, based on the tests of significance carried out in this study, it is found that the drop in the factor value cannot be considered statistically significant. In the case of weekend (Fig. 5c), the plots for cold and truck traffic indicate upward and downward trends that are not statistically significant. In summary, the partial effects of cold variable on daily truck traffic factors are insignificant.

\section{The hourly model}

To confirm the findings observed through daily truck traffic model, hourly dummy-variable regression model is structured to analyze the impact of winter weather on hourly truck traffic. Before conducting hourly modeling, hourly truck volume patterns were compared using pattern recognition algorithm such as minimum square error (MSE) used in the research conducted by Bagheri et al. [17]. It is noted that hourly volume pattern is pretty much consistent irrespective of different cold categories. Hourly snowfall data are not available in Environment Canada climate database. Therefore, the relationships between hourly truck traffic volume and weather conditions were mapped with one quantitative variable (i.e., EHVF) and one categorical variable (i.e., seven categories). The hourly dummy-regression model structure is given in Eq. 2:

$$
\begin{aligned}
y_{i} & =f(\text { expected hourly volume factor, temperature }) \\
& =\beta_{1} E H V F+\sum_{j=1}^{6} \gamma_{j} C C_{i} j+\xi_{i}
\end{aligned}
$$

where $E H V F$ is the expected hourly volume factor and others have the same definition with Eq. 1.

Table 4 Results of hourly factor model for truck traffic using dummy-variable regression for weekday

\begin{tabular}{lll}
\hline Variables & Truck traffics & Seven fitted regression equations for each cold category for trucks \\
\hline EHVF & $1.003(0.004616)^{* * *}$ & $\hat{Y}_{\text {baseline }}=1.003 \times E H V F-0.001549$ \\
Baseline & $-0.001549(0.069444)^{* *}$ & $\hat{Y}_{\mathrm{cc} 1}=1.003 \times E H V F+0.00009059$ \\
$\mathrm{CC}_{1}$ & $0.00009059(0.0003792)$ & $\hat{Y}_{\mathrm{cc} 2}=1.003 \times E H V F-0.0001575$ \\
$\mathrm{CC}_{2}$ & $-0.0001575(0.0003859)$ & $\hat{Y}_{\mathrm{cc} 3}=1.003 \times E H V F-0.0005765$ \\
$\mathrm{CC}_{3}$ & $-0.0005765(0.0004320)$ & $\hat{Y}_{\mathrm{cc} 4}=1.003 \times E H V F+0.001834$ \\
$\mathrm{CC}_{4}$ & $0.001834(0.0004751)^{* * *}$ & $\hat{Y}_{\mathrm{cc5}}=1.003 \times E H V F-0.0003905$ \\
$\mathrm{CC}_{5}$ & $-0.0003905(0.0006777)$ & \\
$\mathrm{CC}_{6}$ & $-0.00005327(0.0007062)$ & \\
$R^{2}$ & 0.9549 & \\
$F$ & $19,630^{* * *}$ & \\
Change from $R_{\text {Naive }}^{2}$ & 0.0006 & \\
Incremental $F$ statistic & $142.1 * * *$ & \\
Number of hours & 7,487 &
\end{tabular}

Regression coefficients with standard errors (in parentheses)

*** Coefficient is statistically significant at the 0.001 level, ** 0.01 level, * 0.05 level 
Table 5 Results of hourly factor model for truck traffic using dummy-variable regression for weekend

\begin{tabular}{lll}
\hline Variables & Truck traffics & Seven fitted regression equations for each cold category for trucks \\
\hline EHVF & $1.008(0.00963)^{* * *}$ & $\hat{Y}_{\text {baseline }}=1.008 \times E H V F-0.001395$ \\
Baseline & $-0.001395(0.0004098)^{* * *}$ & $\hat{Y}_{\mathrm{cc} 1}=1.008 \times E H V F-0.000007771$ \\
$\mathrm{CC}_{1}$ & $-0.000007771(0.0003103)$ & $\hat{Y}_{\mathrm{cc} 2}=1.008 \times E H V F+0.00002578$ \\
$\mathrm{CC}_{2}$ & $0.00002578(0.0002999)$ & $\hat{Y}_{\mathrm{cc} 3}=1.008 \times E H V F-0.00039660$ \\
$\mathrm{CC}_{3}$ & $-0.0003966(0.0003326)$ & $\hat{Y}_{\mathrm{cc} 4}=1.008 \times E H V F+0.0004454$ \\
$\mathrm{CC}_{4}$ & $0.0004454(0.0003789)$ & $\hat{Y}_{\mathrm{cc5}}=1.008 \times E H V F+0.001268$ \\
$\mathrm{CC}_{5}$ & $0.001268(0.0004899)^{* *}$ & \\
$\mathrm{CC}_{6}$ & $-0.0006666(0.0004620)$ & \\
$R^{2}$ & 0.9372 & \\
$F$ & $5,044^{* * *}$ & \\
Change from $R_{\text {Naive }}^{2}$ & 0.0007 & \\
Incremental $F$ statistic & $4.31^{* * *}$ & \\
Number of hours & 2,712 & \\
\hline Regrsion & & \\
\hline
\end{tabular}

Regression coefficients with standard errors (in parentheses)

*** Coefficient is statistically significant at the 0.001 level, ** 0.01 level, * 0.05 level
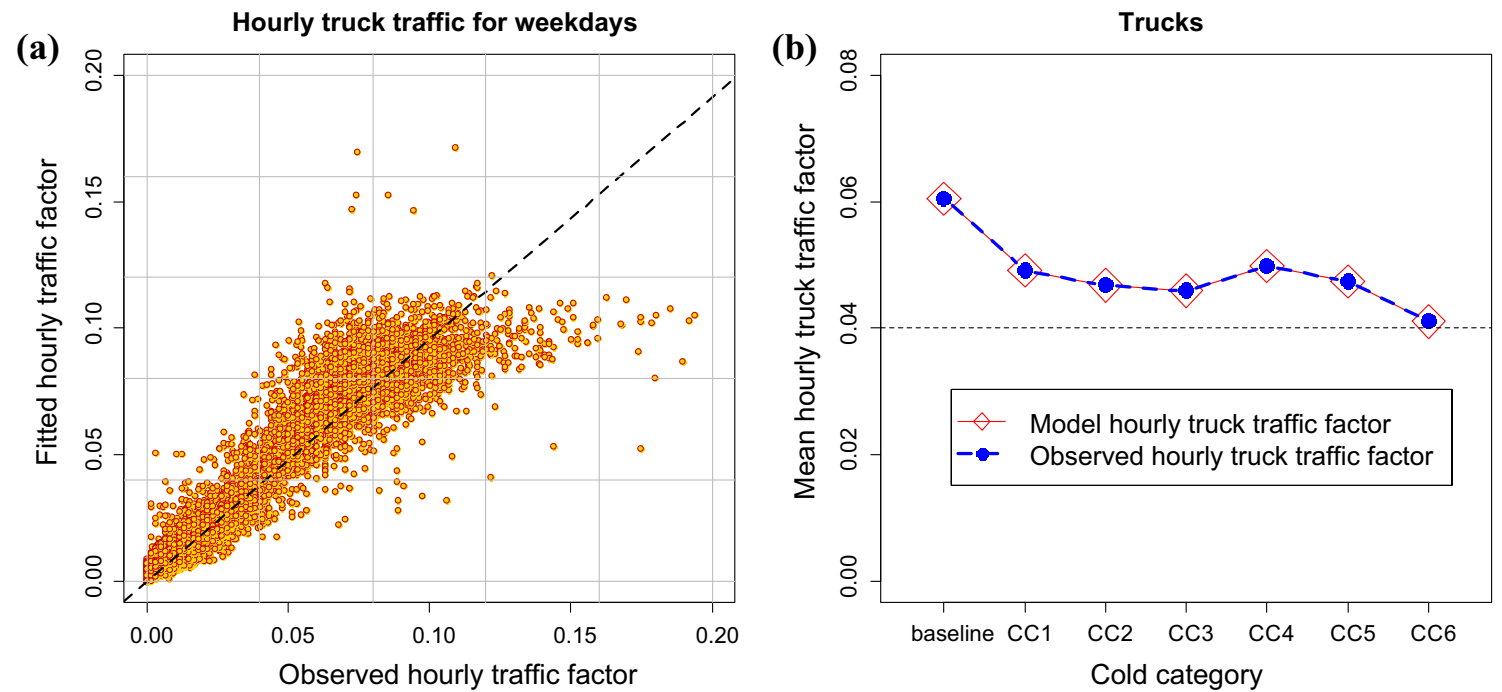

Fig. 6 Results of dummy-variable hourly regression models of weekdays for trucks. a Scatter plot for fitted and observed factors and $\mathbf{b}$ line plot for modeled and observed factors for cold category

Table 4 presents the hourly truck traffic weekday model and hourly weekend truck model is presented in Table 5 along with the statistical test results. The $R^{2}$ values for all hourly models are greater than 0.93 , and the $F$ statistic value is statistically significant at 0.001 level. The incremental $F$ statistic confirms that the inclusion of dummy variables is statistically significant at 0.0001 level. Inclusion of cold category increases the power of explanation of models. However, the statistical importance of individual coefficients evaluated by the $t$ statistic is not significant for all cold categories excepting for some cold categories. In other words, the hourly truck traffic volume is also not significantly affected by the cold categories for both weekdays and weekend. It is the same result as observed at daily truck traffic volumes.

The estimated and observed hourly truck traffic factors are depicted in Figs. 6a and 7a. The accuracy of the calibrated models in terms of estimating the mean hourly truck traffic factor for the seven cold categories is shown with line graphs in Figs. $6 \mathrm{~b}$ and $7 \mathrm{~b}$.

The partial effect of EHVF and cold on hourly truck volume is presented graphically in Figs. 8 and 9. The partial effect of EHVF on hourly volume factor is generated by fixing the temperature at a weighted mean value for 

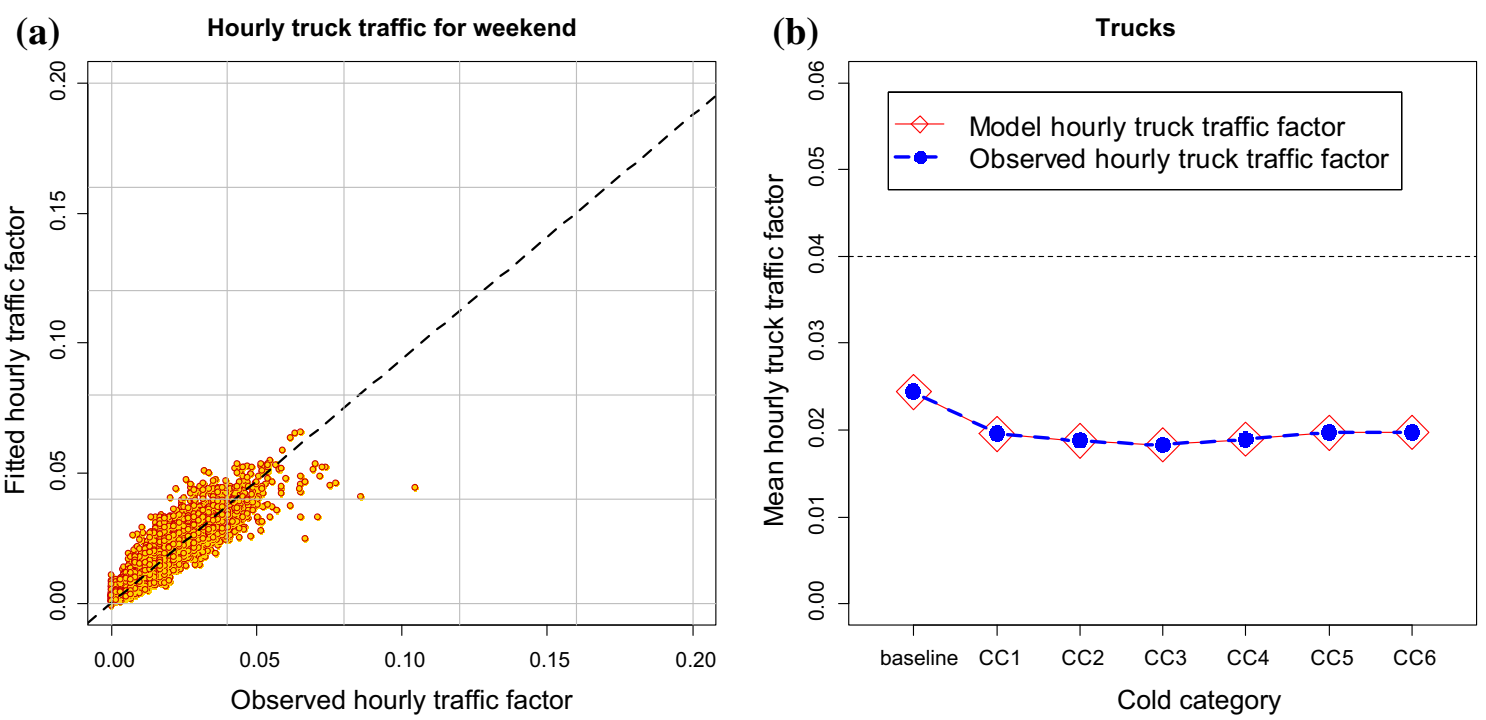

Fig. 7 Results of dummy-variable hourly regression models of weekends for trucks. a Scatter plot for fitted and observed factors and $\mathbf{b}$ line plot for modeled and observed factors for cold category
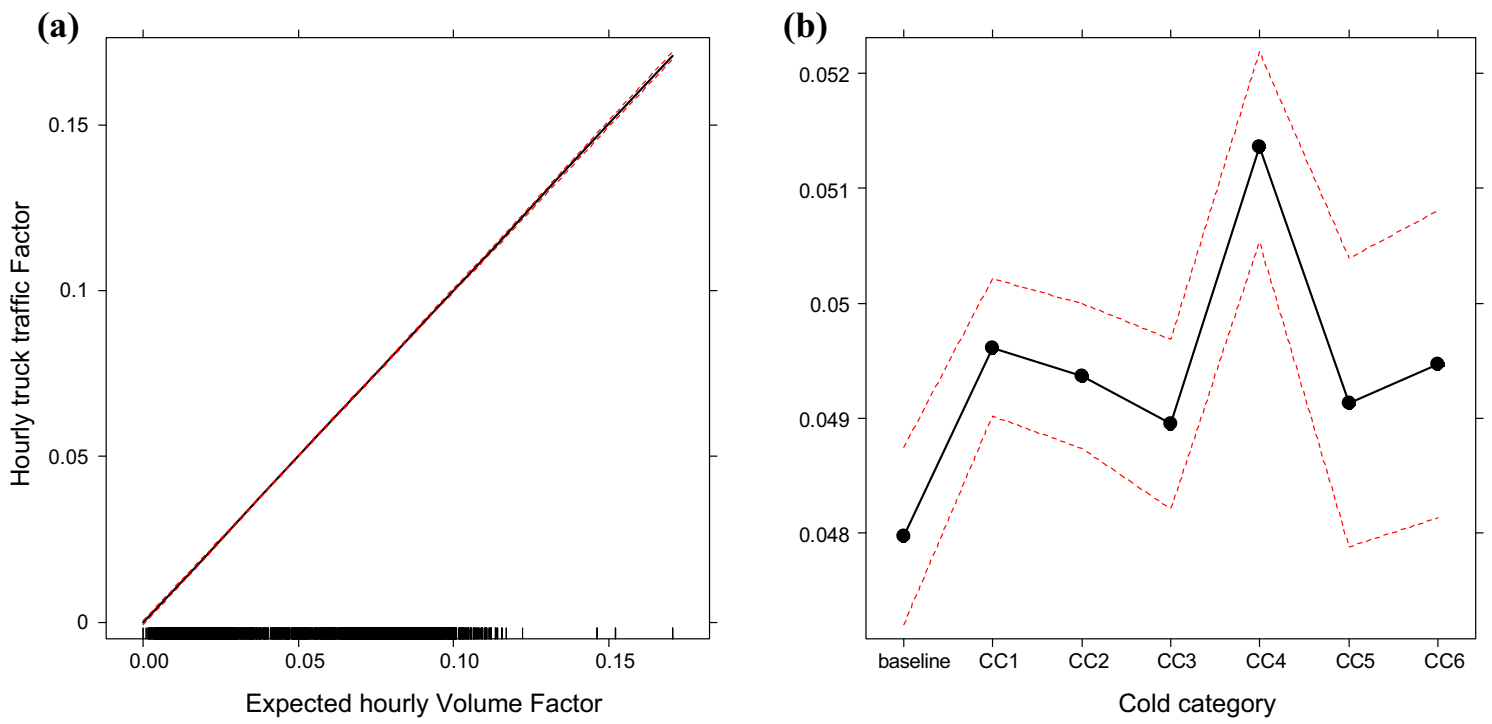

Fig. 8 Partial effect of EHVF and cold on hourly weekday truck volume. a Effect of EHVF on hourly volume and b effect of COLD on hourly volume

the seven cold categories. These plots are shown in Fig. 8a for weekdays and in Fig. 9a for weekend. The partial effect of cold is plotted in Figs. $8 \mathrm{~b}$ and $9 \mathrm{~b}$.

Figure 8a for weekday and Fig. 9a for weekend clearly show a similar positive trend between EHVF and the hourly truck traffic volumes. The partial effect of cold categories on weekday hourly truck traffic is presented in Fig. 8b, and the mean hourly traffic factor does not appear to be changed considerably except for $\mathrm{CC} 4$. A very small amount of increase in the mean hourly factor (0.049-0.0515) is observed between CC3 and CC4.
However, it can be interpreted into marginal increase in terms of real truck number (1-2 vehicles) based on the parameter of annual average daily truck traffic (AADTT) for the study site. For other cold categories, based on the tests of significance carried out in this study, it is found that the drop (or increase) in the hourly traffic factor cannot be considered statistically significant. In the case of weekend (Fig. 9b), the plot seemingly indicates upward and downward patterns that, however, are not statistically significant. In summary, the partial effects of cold variable on hourly truck traffic factors are insignificant. 
(a)

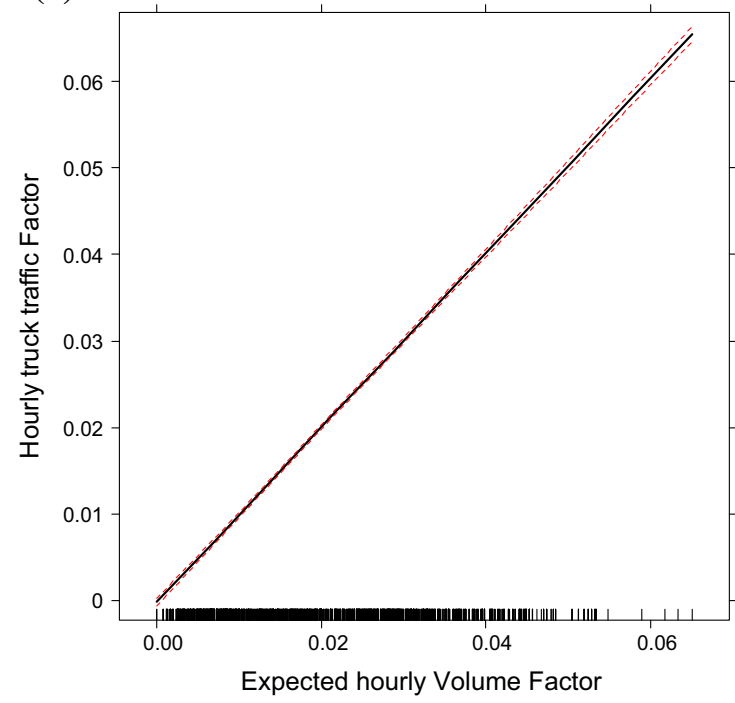

(b)

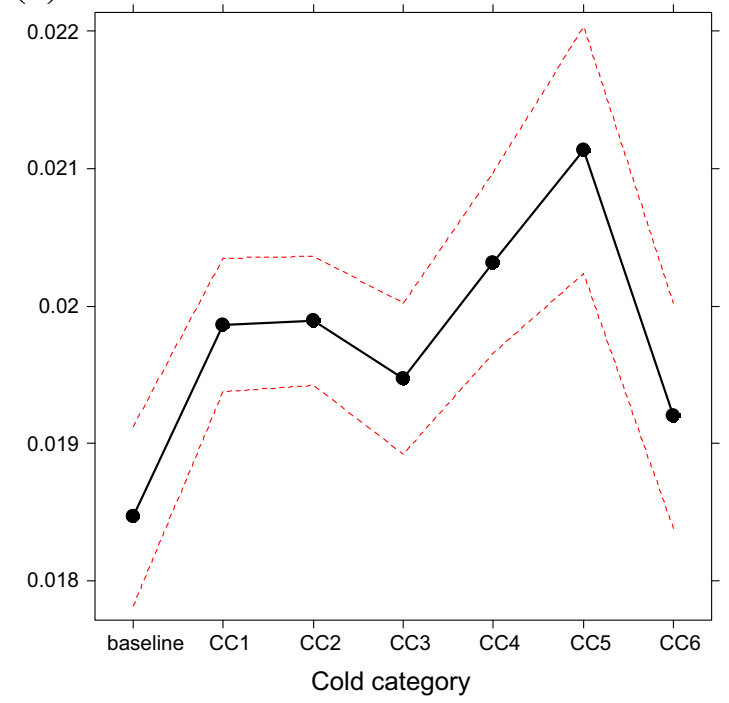

Fig. 9 Partial effect of EHVF and cold on hourly weekend truck volume. a Effect of EHVF on hourly volume and $\mathbf{b}$ effect of COLD on hourly volume

\section{Summary and conclusions}

The literature clearly indicates that severe weather conditions trigger variations in highway traffic. However, past studies in this area are limited to total traffic. Understanding of truck traffic variations (or behavior) under severe weather conditions could provide useful information for transportation planning and engineering applications. An attempt has been made in this study to quantify the truck traffic variations under different weather conditions (mainly Snow and Cold). Vehicle classification data from the WIM site located on a highway site (LEDUC) in the province of Alberta, Canada, are used in this study. The WIM traffic data are grouped into three truck classes: single-unit trucks, single-trailer, and multi-trailer units. The association of truck type distribution with the winter months is examined by means of two statistical tests: $\chi^{2}$ and BP distribution tests. Based on the combined and BP test results, it can be concluded that the truck type distribution is not associated with the winter months for the LEDUC site. These findings have practical implications for rationalization of the length and frequency of traffic counts including classified traffic monitoring programs throughout the year. For example, a short duration traffic count can be taken even during winter season to get reasonably good estimates of truck traffic on highways like studied in this research. The knowledge about independency of truck type distribution with various seasons is likely to help in effective traffic monitoring and estimation of the highway planning and design parameters like AADTT, ADTT, and design hour truck volume. Transportation authority can dispatch maintenance fleets based on regular schedule irrespective of the severity of winter weather conditions to the highway studied in this research.

A dummy-variable regression model on the basis of daily and hourly truck traffic volume is formulated and calibrated for developing the winter weather truck traffic model. Separate models are developed for weekday and weekend truck traffic. The calibrated models are tested for statistical significance of the independent variables using the standard test statistics of $R^{2}, F$ test, incremental $F$ test, and $t$ test. The truck volume is not significantly affected by the snowfall or the cold category variables. Trucks (or commercial vehicles) are usually required to follow rigid schedules to complete their mandatory travel irrespective of severe weather conditions. These kinds of businessoriented mandatory movements are most likely to generate unique truck travel patterns even when weather is unfavorable for making a trip. The conclusions of this study are based on 5 years of WIM data collected from a single site in the province of Alberta. Further research work is currently underway to study the remaining five WIM sites, which are operating on highway segments carrying provincial and interprovincial truck traffic. Future research will also focus on interaction impacts of snow and cold variables on truck traffic.

Acknowledgments The authors are grateful towards the Natural Science and Engineering Research Council of Canada (NSERC), the Faculty of Graduate Studies at the University of Regina, and Saskatchewan Government Insurance (SGI) for their financial support. The authors also thank Alberta Transportation for providing the WIM data used in this study.

Open Access This article is distributed under the terms of the Creative Commons Attribution 4.0 International License (http:// 
creativecommons.org/licenses/by/4.0/), which permits unrestricted use, distribution, and reproduction in any medium, provided you give appropriate credit to the original author(s) and the source, provide a link to the Creative Commons license, and indicate if changes were made.

\section{References}

1. D Sandeep, Sharma S (2008) Impact of cold and snow on temporal and spatial variations of highway traffic volumes. J Transp Geogr 16(5):358-372. doi:10.1016/j.jtrangeo.2007.12.003

2. Knapp KK, Smithson LD (2000) Winter storm event volume impact analysis using multiple-source archived monitoring data. In: Transportation Research Record: Journal of the Transportation Research Board, No. 1700, Transportation Research Board of the National Academies, Washington, DC, pp 10-16. doi:10. 3141/1700-03

3. Fox John (2011) An R companion to applied regression. SAGE Inc., Thousand Oaks

4. R Development Core Team (RDCT) (2010) R: A Language and Environment for Statistical Computing. R Foundation for Statistical Computing, Vienna, Austria, ISBN 3-900051-07-0

5. Maze TH, Agarwal M, Burchett GD (2006) Whether weather matters to traffic demand, traffic safety, and traffic operations and flow. In: Transportation Research Record: Journal of the Transportation Research Board, No. 1948, Transportation Research Board of the National Academies, Washington, DC, pp 170-176. doi: 10.3141/1948-19

6. Keay K, Simmonds I (2005) The association of rainfall and other weather variables with road traffic volume in Melbourne, Australia. Acc Anal Prev 37(1):109-124. doi:10.1016/j.aap.2004.07. 005

7. Hassan YA, Barker JJ (1999) The impact of unseasonable or extreme weather on traffic activity within Lothian region, Scotland. J Transp Geogr 7(3):209-213. doi:10.1016/S0966-6923(98)00047-7
8. Changnon SA (1996) Effects of summer precipitation on urban transportation. Clim Change 32(4):481-494

9. Hanbali RM, Kuemmel DA (1993) Traffic volume reduction due to winter storm conditions. In: Transportation Research Record: Journal of the Transportation Research Board, No. 1387, Transportation Research Board of the National Academies, Washington, DC, pp 159-164

10. Environment Canada (EC) (2010) Weather Office, Gatineau, Quebec, Canada. www.climate.weatheroffice.gc.ca/climateData/ canada_e.html. Accessed 20 Oct 2010

11. Andrey J, Olley R (1990) Relationships between weather and road safety, past and future directions. Climatol Bull 24(3): $123-137$

12. Environmental System Research Institute Inc. (ESRI) (2010) ArcGIS 10 Help Library: Geographic Information System (GIS). ArcGIS 10, Redlands

13. Wyman JH, Braley GA, Stephens RI (1985) Field evaluation of FHWA vehicle classification categories. Publication DTFH-7180-54-ME-03. FHWA, U.S. Department of Transportation, Washington, DC

14. Liu Z, Sharma S (2006) Statistical investigations of statutory holiday effects on traffic volumes. In: Transportation Research Record: Journal of the Transportation Research Board, No. 1945, Transportation Research Board of the National Academies, Washington, DC, pp 40-48. doi:10.3141/1945-05

15. Wayne WD (1990) Applied nonparametric statistics, 2nd ed. PWS-KENT Publishing Company

16. Roh H-J, Datla S, Sharma S (2012) Impact of severe winter conditions on highway truck traffic. In: 9th international transportation specialty CSCE annual conference TRA-1006, 6-9 June 2012, Edmonton, AB, Canada

17. Bagheri Ehsan, Zhong Ming, Christie Janes (2014) Improving AADT estimation accuracy of short-term traffic counts using pattern matching and Bayesian statistics. $J$ of Transp Eng 141(6):A4014001. doi:10.1061/(ASCE)TE.1943-5436.0000528 